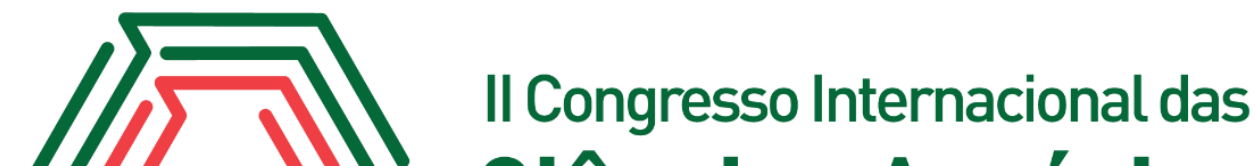 Ciências Agrárias COINTER - PDVAgro 2017
}

\section{INFLUÊNCIA DE DIFERENTES DOSES DE NITROGÊNIO SOBRE DIÂMETRO DO CAULE E ALTURA DE PLANTAS DE SOJA NO ESTÁGIO VEGETATIVO}

\begin{abstract}
Apresentação: Pôster
Nicole Raquel Pinto Cardoso ${ }^{1}$; Adrianne Braga da Fonseca ${ }^{2}$; Bruna Sayuri Fujiyama ${ }^{3}$; José Ribamar Costa $\mathrm{Netto}^{4}$; Mário Lopes da Silva Júnior ${ }^{5}$
\end{abstract}

\section{Introdução}

A soja é cultivada em todas as regiões do Brasil, embora com predominância nas Regiões Sul e Centro-Oeste, que respondem por $93 \%$ da produção. Na Região Norte, a soja é cultivada em Tocantins, no sul do Pará, em Roraima e em Rondônia. No Nordeste, ela está presente nos Estados do Maranhão, do Piauí, da Bahia e de Alagoas. No Sudeste, é cultivada em São Paulo e Minas Gerais (EMBRAPA, 2005).

A cultura representa a maior área cultivada, seguida pelas tradicionais culturas de milho e cana-de- açúcar, bem como o maior consumo de fertilizantes. O custo de $1 \mathrm{t}$ de fertilizante equivale a aproximadamente 20,7 sc de $60 \mathrm{~kg}$ de soja. Dentre os fatores de produtividade, o manejo químico do solo associado a fatores climáticos é ainda o que mais limita a produtividade dessa cultura (VITTI et al. 2000).

Segundo alguns autores, a aplicação de N mineral na cultura da soja eleva o custo de produção, pois em alguns casos recomenda-se o uso de pequenas doses de N (20 a $30 \mathrm{~kg}$ de N ha-1) aplicadas na semeadura, também chamadas de doses de "arranque", cuja finalidade é de disponibilizar $\mathrm{N}$ às plantas até o início da nodulação e que mesmo na presença de adequada inoculação, o suprimento de nitrogênio no solo para o crescimento inicial da soja, mostrou-se de

\footnotetext{
${ }^{1}$ Agronomia, Universidade Federal Rural da Amazônia, nicolepcardoso@gmail.com

2 Agronomia, Universidade Federal Rural da Amazônia, adrianne.braga@gmail.com

${ }^{3}$ Agronomia, Universidade Federal Rural da Amazônia, sayurifujiyama@hotmail.com

${ }^{4}$ Agronomia, Universidade Federal Rural da Amazônia, jrnetto@gmail.com

${ }^{5}$ Doutor, Universidade Federal Rural da Amazônia, mario.silva@ufra.edu.br
} 
grande relevância (ARAÚJO e CARVALHO, 2006 apud SILVA et al. 2008).

Nesse sentido, com o intuito de gerar informações relevantes e importantes a respeito da utilização de nitrogênio na cultura da soja, realizou-se o presente trabalho, com objetivo de avaliar o efeito de diferentes doses de adubação nitrogenada no diâmetro do caule e altura de plantas de soja cultivadas em ambiente controlado.

\section{Fundamentação Teórica}

O nitrogênio é um dos nutrientes requeridos em maiores quantidades pela cultura da soja, e isso se deve pelo fato de que como a soja representa a principal cultura do agronegócio brasileiro, sua grande importância deve-se a composição dos seus grãos, onde contem em média grande parte do nitrogênio absorvido do solo e que após sua maturidade, seus produtos são utilizados tanto na alimentação animal quanto vegetal (EMBRAPA, 2001).

Além disso, a maior parte do nitrogênio encontrado na planta é obtida através da fixação biológica de nitrogênio, porém com o desenvolvimento de materiais com grande potencial produtivo, alguns estudos tem sidos realizados a fim de estudar a melhor resposta da cultura ao fornecimento do nutriente realizadas principalmente via adubação de base (MENDES et al. 2008).

\section{Metodologia}

O presente trabalho foi conduzido em casa de vegetação do Setor de Ciência do Solo, da Universidade Federal Rural da Amazônia, Campus Belém.

O experimento foi conduzido em vasos de $5 \mathrm{~kg}$, em solo da camada de 0 a $20 \mathrm{~cm}$ de Latossolo Amarelo textura muito argilosa proveniente de área não cultivada de Paragominas/ $\mathrm{Pa}$. O solo coletado foi peneirado em malha de $4 \mathrm{~mm}$ de diâmetro.

O delineamento experimental foi blocos ao acaso, com 5 tratamentos, sendo 4 doses de $\mathrm{N}$ 25, 50, 75 e $100 \mathrm{~g}$ de $\mathrm{N}$ por quilo de solo (EMBRAPA, 1991) - e um tratamento testemunha (0 g de $\mathrm{N}$ por quilo de solo) e 5 repetições, totalizando 25 unidades experimentais. A cultivar utilizada foi M 8644 IPRO da Monsoy.

O desbaste foi realizado 7 dias após emergência e a aplicação dos tratamentos foi realizada 8 DAE através de solução nutritiva de $\mathrm{NH}_{4} \mathrm{Cl}$, juntamente com os demais nutrientes. Foram mantidas apenas duas plantas, cultivadas em solo com capacidade de campo a 80\%. Realizou-se coleta de dados referentes a diâmetro do caule e altura da planta aos 20 DAE, momento em que as plantas 
estavam no estádio V4. Os dados coletados foram submetidos à análise estatística pelo Software Assistat.

\section{Resultados e Discussões}

O diâmetro do caule de plantas de soja no estádio V4 não variou entre os diferentes tratamentos a que foram submetidas. De acordo com análise estatística o F apresentou valor de 0.31, ou seja, não significativo, desta forma as diferentes doses de Nitrogênio não interferem no tamanho do diâmetro do caule no estádio vegetativo da soja (Gráfico 1).

Gráfico 1: Diâmetro do caule de plantas de soja em função das doses de N. Fonte: Própria

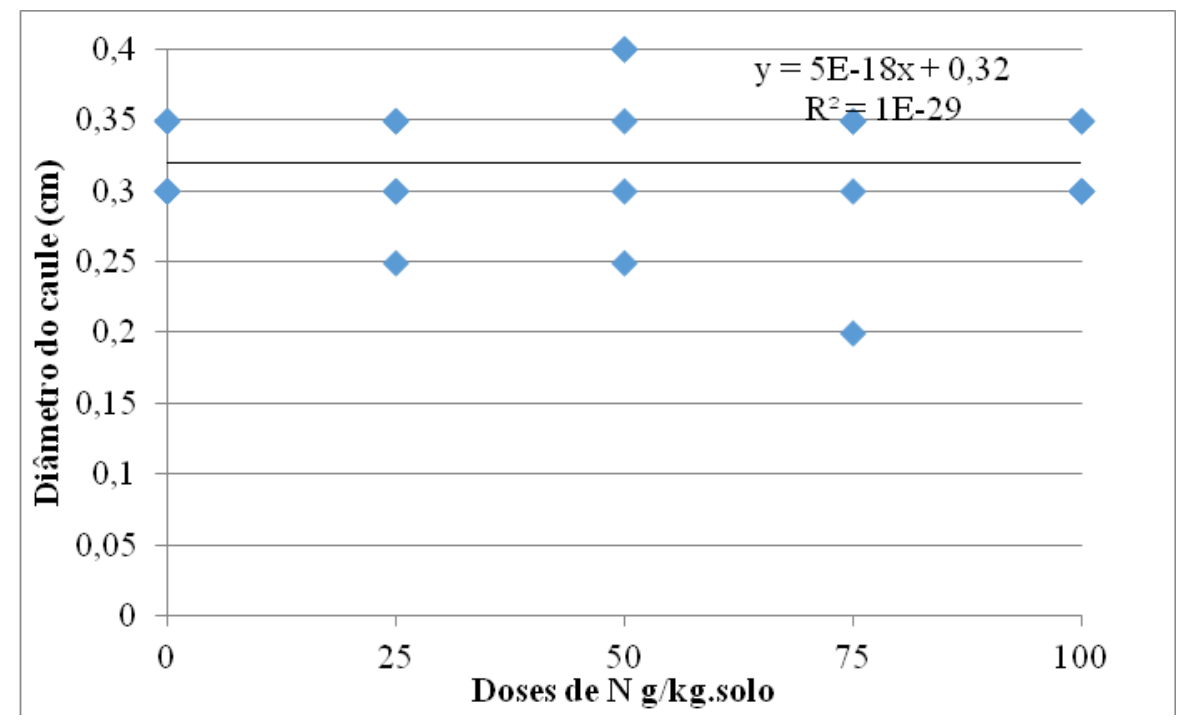

Quanto aos dados de altura das plantas, observou-se que também não houve variação significativa $(\mathrm{F}=2.05)$, ou seja, diferentes doses de Nitrogênio não apresentaram influência significativa na altura das plantas de soja aos 20 DAE. Porém, as diferentes doses de nitrogênio tiveram maior influência na variável 'altura' em comparação a variável 'diâmetro', ainda que muito pequena (Gráfico 2). 
Gráfico 2: Altura de plantas de soja em função das doses de N. Fonte: Própria

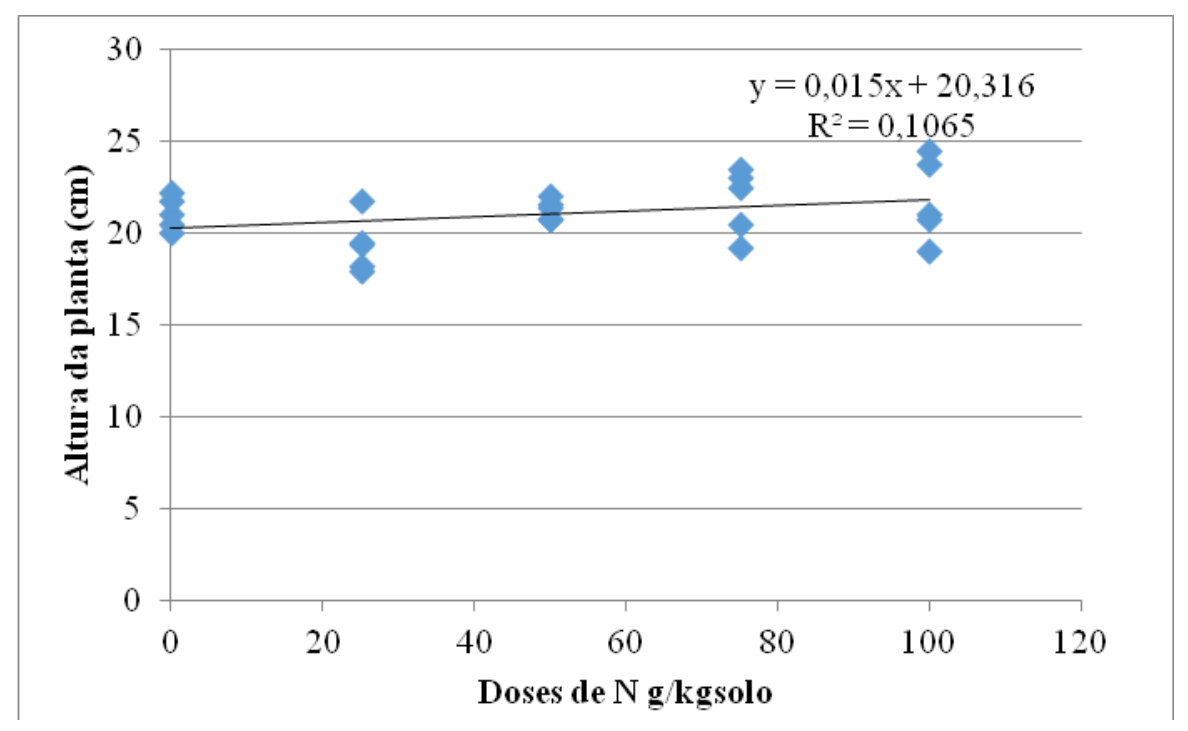

Esta situação pode ser justificada pelo fato de que no estádio V4 o teor de $\mathrm{N}$ acumulado na planta é menor que 20\%. (OLIVEIRA JÚNIOR et. al, 2016) A absorção de N na cultura da soja é maior a partir do estádio R3 (OLIVEIRA JÚNIOR et. al, 2016), o que sugere que no estádio reprodutivo, diferentes doses de $\mathrm{N}$ podem afetar o diâmetro do caule e altura das plantas.

\section{Conclusões}

O Nitrogênio é um nutriente essencial para o desenvolvimento das plantas principalmente na produção de biomassa, porém, no estádio vegetativo da cultura da soja não interfere significativamente no diâmetro do caule e altura das plantas. Devido a ser um elemento estrutural, pode interferir nestes parâmetros em estádios mais avançados.

\section{Referências}

EMBRAPA, Manual de segurança e qualidade para a cultura da soja - Brasília, DF : Transferência de Tecnologia, 2005.

EMBRAPA. Métodos de Pesquisa em Fertilidade do Solo - Brásilia, DF: 1991

EMBRAPA. Centro nacional de Pesquisa de Soja. Fixação biológica do nitrogênio na cultura da soja. Embrapa Soja. Circular Técnica, 35. ago/2001. Londrina: Embrapa Soja, 2001. 48p.

MENDES, I. C. et al. Adubação nitrogenada suplementar tardia em soja cultivada em 
latossolos do cerrado. Pesquisa Agropecuária Brasileira. v. 43, n. 8, p. 1053-1060, Brasília: 2008.

SANTOS, J. T.; LUCAS, F. T.; FRAGA, D. F.; OliVEIRA, L.; PEDROSO NETO, J. C. Adubação nitrogenada, com e sem inoculação de semente, na cultura da soja.

SILVA, A. F. da; CARVALHO, M.A.C. de; SCHONINGER, E.L.; MONTEIRO, S.; CAIONE, G.; SANTOS, P.A. Doses de inoculante e nitrogênio na semeadura da soja em área de primeiro cultivo. Bioscience Journal. v.27, n.3, p.404-412, 2011.

VITTI, G. C.; TREVISAN, W.; Manejo de macro e micronutrientes para alta produtividade da soja. Informações agronômicas. $n^{\circ} 90$ - jun/2000 